Original Article

\title{
FORMULATION AND IN VITRO EVALUATION OF COMBINED FLOATING-BIOADHESIVE TABLETS OF IMATINIB MESYLATE
}

\author{
RABI NARAYAN PANIGRAHY ${ }^{1,2}$, SUSANTA KUMAR PANDA ${ }^{1}$, PRABHAKAR REDDY VEERAREDDY3 \\ ${ }^{1}$ Royal College of Pharmacy and Health Sciences, Andhapasara Road, Brahmapur, Odisha-760002, ${ }^{2}$ School of Pharmacy, Nalla Narasimha \\ Reddy Education Society's Group of Institutions, Ghatkesar, Hyderabad-500088, ${ }^{3}$ College of Pharmacy, Palamuru University, \\ Mahbubnagar, Telangana-509001 \\ Email: rabi.papu@gmail.com
}

Received: 04 Apr 2017 Revised and Accepted: 21 Sep 2017

\begin{abstract}
Objective: Gastro retentive drug delivery system (GRDDS) pertaining to its attributes like gastric retention time and the extended drug release profile has significantly improved patient compliance. The objective of the present study was to formulate and evaluate a stomach-specific floating-bioadhesive tablets (FBTs) of imatinib mesylate (IM) for prolonged residence in the stomach in the treatment of gastrointestinal stromal tumours (GIST).

Methods: All the FBTs were prepared with hydroxypropyl methyl cellulose (HPMC) K 15M, guar gum, sodium alginate, and carbopol 971P using direct compression technique. Physical characterization, in vitro dissolution, swelling characteristics, the mucoadhesive force along with data analysis was done for each FBT.

Results: The pre-compression characteristics of powder mixtures found to be satisfactory for all formulation batches. The results of physical evaluation for all batches were complying with pharmacopoeia specification. The swelling index for all formulation batches was approximately $100 \%$ after $8 \mathrm{~h}$. The bioadhesive force (mean \pm SD) reported in a range of $0.05 \pm 0.09$ to $0.18 \pm 0.06 \mathrm{~N} / \mathrm{m}^{2}$. It was observed that the release rate of FBTs was decreased with an increment of viscosity and concentration of the polymer. Formulation batches IB1, IB2, IB4, IB5, IB6, IB9, IB10, IB11, and IB13 follows Higuchi Matrix model kinetics; whereas IB3, IB7, IB8, and IB12 follows Korsmeyer-Peppas model kinetics.
\end{abstract}

Conclusion: Formulation batch IB9 reported a considerable swelling index, floating behaviour, more bioadhesive strength with uniform drug release pattern. Therefore formulation batch IB9 was selected as optimized batch and kept for further evaluation studies.

Keywords: Gastro-retentive, Imatinib mesylate, Swelling index, Bioadhesive strength

(C) 2017 The Authors. Published by Innovare Academic Sciences Pvt Ltd. This is an open access article under the CC BY license (http://creativecommons.org/licenses/by/4.0/) DOI: http://dx.doi.org/10.22159/ijpps.2017v9i11.18894

\section{INTRODUCTION}

The most expedient and ideal means of any drug delivery to the systemic circulation is oral administration [1]. Among administration routes utilized for drug delivery systems (DDS), oral DDS has recently been of adding interest in the pharmaceutical field to achieve improved therapeutic advantages, such as ease of dosing administration, patient compliance, and flexibility in formulation [2]. Oral DDS are categorized into immediate release and modified release systems. However, the conventional immediate-release oral dosage form has a problem of a transient overdose followed by a long period of under-dosing, which can be overcome by a designing controlled DDS [2]. The modern development in the technology of oral DDS has outcome numerous novel pharmaceutical products, importantly the controlled release DDS to overcome the mentioned hitches with immediate-release oral dosage forms [3]. Gastroretentive drug delivery system (GRDDS) pertaining to its attributes like gastric retention time and drug release profile for an extended time has significantly improved patient compliance [4]. Further, certain intrinsic drawbacks of the conventional oral DDS have also kindled the interest to the development of this novel DDS [5] Various approaches have been proposed to control the gastric residence of the DDSs in the upper part of the gastri intestinal (GIT) tract including floating DDS, high-density DDS, mucoadhesive systems, swelling and expanding DDS, modified shape systems, and other delayed gastric devices [6]. Imatinib mesylate (IM), an anticancer drug with a pKa value of 12.45 in an acidic environment and 8.27 in basic environment shows a discrepancy in its solubility profile [7]. It is reported soluble in acidic condition $(\mathrm{pH}<5.5)$ but very slightly soluble to insoluble in neutral and alkaline aqueous buffer solutions [8]. Furthermore, it has high absorption in the upper part of the GIT. In contrast, a conventional tablet of IM pertaining to their rapid and relatively high peak blood levels necessitates repeated administration to maintain the steady-state plasma drug level. This might produce side effects, decreased effectiveness and poor therapeutic management [9]. Floating dosage forms can provide gastric retention when the stomach is full after a meal. Thus, the buoyancy of a floating DDS in the stomach may be limited to only 3-4 h. Furthermore, floating systems do not always release the drug at the expected site. In addition, during peristalsis, or when the stomach is full, it is quite likely that the tablet becomes dislodged from the stomach mucosa wall in a bioadhesive system [3]. In concern to the mentioned approaches, a combination of the floatingbioadhesive system (FBS) would overcome those drawbacks and would significantly improve the therapeutic efficacy of the involved drug. The objective of the present study was to formulate and evaluate a stomach-specific floating-bioadhesive tablet (FBT) of IM for prolonged residence in the stomach in the treatment of gastrointestinal stromal tumours (GIST).

\section{MATERIALS AND METHODS}

\section{Materials}

IM was received as a gift sample from Celon lab, Hyderabad. Sodium bicarbonate, citric acid, and carbopol 971P were obtained from Loba chemicals. Guar gum was supplied from Noveon chemicals. Microcrystalline cellulose (MCC), hydroxypropyl methyl cellulose (HPMC) K 15M, and sodium alginate were brought from Signet chemical corporation, Mumbai. All other reagents are of analytical or pharmaceutical grade and deionized water was obtained by reverse osmosis.

\section{Pre-compression characteristics of powder blend}

The characteristic parameters of the formulated mixture were evaluated. The flow behavior was determined by the funnel method. 
The bulk density, tapped density, and Carr's index were determined and calculated [6].

\section{Preparation of FBTs}

All the FBTs of IM were prepared by direct compression technique [3]. The ingredients were accurately weighed and blended homogeneously in a mortar according to table 1 . The blended mixture was passed through sieve no. 30 . Finally, talc, polyethene glycol, and magnesium stearate were added to the mixture as a lubricant to promote easy ejection and good anti-sticking property [9]. The homogeneously blended mixture was then compressed on a rotary tablet press (RIMEK, 10 stations, KEL) with $10 \mathrm{~mm}$ concaves punch with a compression force of $250 \mathrm{~kg} / \mathrm{cm}^{2}$.

The tablet hardness was kept in the range $5-6 \mathrm{~kg} / \mathrm{cm}^{2}$ tested on Monsanto tablet hardness tester. At least 30 tablets were prepared for each formulation in a single batch.

Table 1: Formulation of FBTs

\begin{tabular}{|c|c|c|c|c|c|c|c|c|c|c|}
\hline Ingredients/Formulation bathes & IM & HPMC K 15M & Guar gum & SA & Carbopol 971P & SB & CA & PVP K30 & MCC & Talc andMS \\
\hline IB1 & 100 & 48 & 12 & - & - & 40 & 10 & 50 & 30 & 10 \\
\hline IB2 & 100 & 45 & 15 & - & - & 40 & 10 & 50 & 30 & 10 \\
\hline IB3 & 100 & 40 & 20 & - & - & 40 & 10 & 50 & 30 & 10 \\
\hline IB4 & 100 & 48 & - & 12 & - & 40 & 10 & 50 & 30 & 10 \\
\hline IB5 & 100 & 45 & - & 15 & - & 40 & 10 & 50 & 30 & 10 \\
\hline IB6 & 100 & 40 & - & 20 & - & 40 & 10 & 50 & 30 & 10 \\
\hline IB7 & 100 & 48 & - & - & 12 & 40 & 10 & 50 & 30 & 10 \\
\hline IB8 & 100 & 45 & - & - & 15 & 40 & 10 & 50 & 30 & 10 \\
\hline IB9 & 100 & 40 & - & - & 20 & 40 & 10 & 50 & 30 & 10 \\
\hline IB10 & 100 & 40 & 10 & 10 & - & 40 & 10 & 50 & 30 & 10 \\
\hline IB11 & 100 & 40 & 10 & - & 10 & 40 & 10 & 50 & 30 & 10 \\
\hline IB12 & 100 & 40 & - & 10 & 10 & 40 & 10 & 50 & 30 & 10 \\
\hline IB13 & 100 & 30 & 10 & 10 & 10 & 40 & 10 & 50 & 30 & 10 \\
\hline
\end{tabular}

All values specified are in milligram (mg); IM, imatinib mesylate; HPMC, hydroxypropyl methylcellulose; SA, sodium alginate; SB, sodium bicarbonate; CA, citric acid; PVP, polyvinyl pyrrolidone; MCC, microcrystalline cellulose; MS, magnesium stearate

\section{Physical characterization and in vitro evaluation of the prepared FBTs}

The physical characterization and in vitro studies were conducted using Indian Pharmacopoeia and USP standard procedures [10,11].

\section{Weight variation}

Twenty tablets were randomly selected from each batch and then accurately weighed by using an electronic balance (Shimadzu, AUWD, Japan).

\section{Thickness}

Ten tablets were randomly selected and the thickness was measured using a Vernier caliper. Results were expressed as mean \pm SD.

\section{Hardness}

The tablet's hardness $(n=5)$ was investigated using Monsanto hardness tester. The hardness of tablets was expressed as mean \pm SD.

\section{Friability}

Ten tablets were randomly selected and the friability was calculated by using Roche friabilator. Results were expressed as mean \pm SD.

\section{Drug content uniformity}

For this at least 30 tablets were randomly selected. Out of 30 tablets, 10 tablets were crushed into fine powder and assayed individually. The powder was dissolved in $500 \mathrm{ml}$ of $0.1 \mathrm{~N} \mathrm{HCl}$, filtered and the specific aliquots were taken and analyzed spectrophotometrically (Shimadzu, SPD-10AVP, Kyoto, Japan) at $237 \mathrm{~nm}$.

\section{Floating behaviour}

The buoyancy lag time of the tablets $(\mathrm{N}=10)$ was studied at $37 \pm 0.5$ ${ }^{\circ} \mathrm{C}$, in $100 \mathrm{ml} 0.1 \mathrm{~N} \mathrm{HCl}$. The time required for the tablet to rise to the surface and float and the total floating time (the duration which the tablet remains buoyant) were recorded.

\section{Swelling characteristics}

The swelling properties of matrices containing IM were determined by placing the tablet in the dissolution test apparatus, in $900 \mathrm{ml} 0.1 \mathrm{~N}$ $\mathrm{HCl}$ at $37 \pm 0.5^{\circ} \mathrm{C}$. The tablets were removed periodically from the dissolution medium, then free water was sucked with bloating paper and, after removing free water, the weight gain was measured $[3,4]$. The swelling characteristics were expressed in terms of the percentage water uptake.

\section{In vitro bio-adhesion study}

The bioadhesive forces of the FBTs were determined by the physical balance method. The pieces of Sheep funds tissue were stored and frozen in saline solution and thawed to room temperature immediately before use. At the time of testing a section of tissue was transferred, keeping the mucosal side out, to the upper glass vial using a rubber band and an aluminum cap. The diameter of each exposed mucosal membrane was $1.1 \mathrm{~cm}$. The vials with the Sheep funds tissue were stored at $37^{\circ} \mathrm{C}$ for $10 \mathrm{~min}$. Next, one vial with a section of tissue was connected to the balance and the other vial was fixed on a height-adjustable pan. A tablet was applied to the lower vial with the help of two pieces of adhesive tape.

The height of the vial was adjusted so that the tablet could adhere to the mucosal tissues in the vial. A constant weight $(10 \mathrm{~g})$ was placed in the upper vial and applied for 2 min, after which it was removed, and the upper vial was then connected to the balance. Weights were added at a constant rate to the pan on the other side of the modified balance of the device until the two vials were separated. The bioadhesive force, expressed as the detachment stress in $\mathrm{N} / \mathrm{M}^{2}$, was determined from the minimum weight required to detach the two vials using the following equation [6].

Force of adhesion $=$ Mucoadhesion in gram $\times 0.0981$

\section{Ex vivo mucoadhesion time}

A modified USP disintegration apparatus was used for determination of the ex vivo residence time. The medium was constituted of $900 \mathrm{ml}(\mathrm{pH} 1.5)$ of $0.1 \mathrm{~N} \mathrm{HCl}$ maintained at $37 \pm 0.5$ ${ }^{\circ} \mathrm{C}$. The sheep gastric mucosa was tangled to the surface of a glass slab and connected vertically to the disintegration apparatus. The FBTs were hydrated using phosphate buffer ( $\mathrm{pH}$ 6.8) and the hydrated surface was carried in contact with the mucosal membrane. The glass slide allowed moving up and down and hence that the tablet was completely immersed in the buffer solution at the lowest point and was out at the highest point. The time taken for complete displacement of the tablet from the mucosal surface was noted [12]. 


\section{In vitro dissolution studies}

The release profiles of FBTs were determined using USP dissolution testing apparatus II (Paddle type). The dissolution test was performed using $900 \mathrm{ml} 0.1 \mathrm{~N} \mathrm{HCl}$, at $37 \pm 0.5{ }^{\circ} \mathrm{C}$ and $50 \mathrm{rpm}$. A sample $(5 \mathrm{ml})$ of the solution was withdrawn from the dissolution apparatus hourly for $12 \mathrm{~h}$, and the samples were replaced with fresh dissolution medium. The absorbance of these samples was measured at $237 \mathrm{~nm}$ [6].

\section{Data analysis}

The data obtained from the dissolution study were fitted into zero order, first order, Higuchi matrix, and Korsmeyer-Peppas model to evaluate the mechanism of drug release and release rate kinetics. Further based on the $r$ value, the best fit model was selected.

\section{RESULTS AND DISCUSSION}

The FBTs were prepared by direct compression method. HPMC K15M was used as a rate controlling polymer (primary polymer) whereas guar gum, sodium alginate, and carbopol 971P were used as bioadhesive polymers (secondary polymer). Sodium bicarbonate and citric acid were used as gas generating agents. MCC was used as diluent. Tablets of formulation batches IB1 to IB9 contain only single bioadhesive polymer in different concentration, while IB10 to IB13 contains a combination of various bioadhesive polymers (table 1 ).

\section{Pre-compression characteristics}

The densities, angle of repose and Carr's compressibility index for all the batches of mixture demonstrates satisfactory flow behaviour. The data has been depicted in table 2 .

Table 2: Pre-compression characteristics of FBTs

\begin{tabular}{|c|c|c|c|c|}
\hline Formulation batches/Charactertics & Bulk density (g/ml) & Tap density $(\mathrm{g} / \mathrm{ml})$ & Carr's index (\%) & Angle of repose $\left({ }^{\circ}\right)$ \\
\hline IB1 & $0.542 \pm 0.07$ & $0.672 \pm 0.03$ & 19.34 & $29 \pm 1.7$ \\
\hline IB2 & $0.537 \pm 0.03$ & $0.67 \pm 0.02$ & 19.85 & $28 \pm 2.0$ \\
\hline IB3 & $0.561 \pm 0.08$ & $0.71 \pm 0.05$ & 21.12 & $30 \pm 1.8$ \\
\hline IB4 & $0.548 \pm 0.01$ & $0.668 \pm 0.05$ & 17.96 & $26 \pm 1.5$ \\
\hline IB5 & $0.58 \pm 0.09$ & $0.694 \pm 0.07$ & 16.42 & $28 \pm 1.2$ \\
\hline IB6 & $0.563 \pm 0.04$ & $0.665 \pm 0.03$ & 15.33 & $25 \pm 1.3$ \\
\hline IB7 & $0.555 \pm 0.02$ & $0.683 \pm 0.06$ & 18.74 & $27 \pm 1.7$ \\
\hline IB8 & $0.572 \pm 0.03$ & $0.692 \pm 0.05$ & 17.34 & $24 \pm 1.3$ \\
\hline IB9 & $0.521 \pm 0.04$ & $0.642 \pm 0.01$ & 18.84 & $22 \pm 1.5$ \\
\hline IB10 & $0.533 \pm 0.05$ & $0.652 \pm 0.07$ & 18.25 & $24 \pm 1.5$ \\
\hline IB11 & $0.523 \pm 0.08$ & $0.648 \pm 0.02$ & 19.29 & $29 \pm 1.8$ \\
\hline IB12 & $0.512 \pm 0.02$ & $0.623 \pm 0.01$ & 17.81 & $27 \pm 1.2$ \\
\hline IB13 & $0.545 \pm 0.07$ & $0.663 \pm 0.01$ & 17.79 & $26 \pm 1.1$ \\
\hline
\end{tabular}

All values are mean \pm SD; SD, Standard deviation

\section{Evaluation of FBTs}

A thickness (mean $\pm \mathrm{SD}$ ) in the range of $3.2 \pm 0.04$ to $3.7 \pm 0.08 \mathrm{~mm}$ was reported in all formulation batches. Hardness (mean \pm SD) was found to be $4.8 \pm 0.2$ to $5.5 \pm 0.5$. Tablet from all batches passed the weight variation test as per USP specification. The percentage friability was $<0.9 \%$, which stated that all tablets were passed the test. The percentage drug content was up to $99 \%$ with some variability observed between formulation batches. The data has been reported in table 3.

Table 3: Evaluation parameters of FBTs

\begin{tabular}{|c|c|c|c|c|c|}
\hline Formulation batches/Charactertics & $\begin{array}{l}\text { Thickness } \\
(\mathrm{mm})^{*}\end{array}$ & $\begin{array}{l}\text { Hardness } \\
\left(\mathrm{kg} / \mathrm{cm}^{2}\right)^{*}\end{array}$ & Friability (\%) & Drug content (\%) & Weight variation \\
\hline IB1 & $3.4 \pm 0.01$ & $5.1 \pm 0.6$ & 0.67 & 99.2 & Passes \\
\hline IB2 & $3.5 \pm 0.03$ & $5.3 \pm 0.1$ & 0.57 & 97.4 & Passes \\
\hline IB3 & $3.7 \pm 0.05$ & $5.2 \pm 0.3$ & 0.72 & 98.2 & Passes \\
\hline IB4 & $3.5 \pm 0.02$ & $5 \pm 0.6$ & 0.58 & 95.1 & Passes \\
\hline IB5 & $3.6 \pm 0.02$ & $5.5 \pm 0.5$ & 0.91 & 91.2 & Passes \\
\hline IB6 & $3.3 \pm 0.07$ & $5.1 \pm 0.3$ & 0.8 & 93.2 & Passes \\
\hline IB7 & $3.7 \pm 0.01$ & $4.8 \pm 0.2$ & 0.56 & 97.1 & Passes \\
\hline IB8 & $3.5 \pm 0.05$ & $4.9 \pm 0.3$ & 0.51 & 99 & Passes \\
\hline IB9 & $3.2 \pm 0.04$ & $5 \pm 0.2$ & 0.84 & 93.5 & Passes \\
\hline IB10 & $3.3 \pm 0.02$ & $5.1 \pm 0.7$ & 0.77 & 94.8 & Passes \\
\hline IB11 & $3.7 \pm 0.08$ & $5.3 \pm 0.4$ & 0.67 & 95.6 & Passes \\
\hline IB12 & $3.7 \pm 0.02$ & $5.4 \pm 0.1$ & 0.75 & 92.9 & Passes \\
\hline IB13 & $3.5 \pm 0.01$ & $5.5 \pm 0.2$ & 0.71 & 93 & Passes \\
\hline
\end{tabular}

*All values are mean \pm SD; SD, Standard deviation

\section{Floating behaviour}

The tablet from all formulation batches reported satisfactory floatation in a range of 18-300 seconds and remained buoyant for more than $8 \mathrm{~h}$ in the dissolution medium with rotation. The data has been presented in table 4 . The buoyancy lag time varies with the amount of sodium bicarbonate and citric acid concerned in the $\mathrm{CO}_{2}$ formation and the concentration of polymers. Furthermore, the ideal matrix or coating material should be highly porous to dissolution media in order to commence rapid generation of $\mathrm{CO}_{2}$ and allow the release of $\mathrm{CO}_{2}$ to initiate floating. In addition, higher water content could lead to greater penetration of the gastric fluid into the tablet leading to faster $\mathrm{CO}_{2}$ generation, thereby reducing the floating lag time. 
Table 4: Floating behaviour of FBTs

\begin{tabular}{lll}
\hline Formulation batches/Characteristics & Buoyancy lag-time (sec)* & Duration of floating (hr) \\
\hline IB1 & $52 \pm 0.9$ & 10 \\
IB2 & $74 \pm 0.4$ & 8 \\
IB3 & $167 \pm 0.5$ & 8 \\
IB4 & $87 \pm 0.3$ & 11 \\
IB5 & $195 \pm 0.2$ & 9 \\
IB6 & $300 \pm 0.7$ & 8 \\
IB7 & $65 \pm 0.1$ & 9 \\
IB8 & $212 \pm 0.5$ & 7 \\
IB9 & $255 \pm 0.4$ & 10 \\
IB10 & $159 \pm 0.3$ & 11 \\
IB11 & $167 \pm 0.6$ & 10 \\
IB12 & $154 \pm 0.5$ & 11 \\
IB13 & $293 \pm 0.8$ & 7 \\
\hline
\end{tabular}

*All values are mean \pm SD; SD, Standard deviation

\section{Swelling behaviours}

Swelling index of all FBTs was calculated periodically at 1, 2, 4 and 8 $\mathrm{h}$ interval. The formulations containing more concentrations of bioadhesive polymer reported additional swelling compared to other formulations. Further, formulation batches with carbopol 971P revealed extraordinary swelling as compared to other two polymers. Furthermore, formulation batch IB9 reported a consistent and high swelling behaviour as compared to other formulations. The graph has been presented in fig. 1. The swelling index was increased with respect to the increment of the concentration of polymers.

This might be pertaining to the mobility of the polymer chains, which varies dependent on the water content of the system. In the case of high water content, polymer chain relaxation takes place with volume expansion resulting in marked swelling of the system [6].

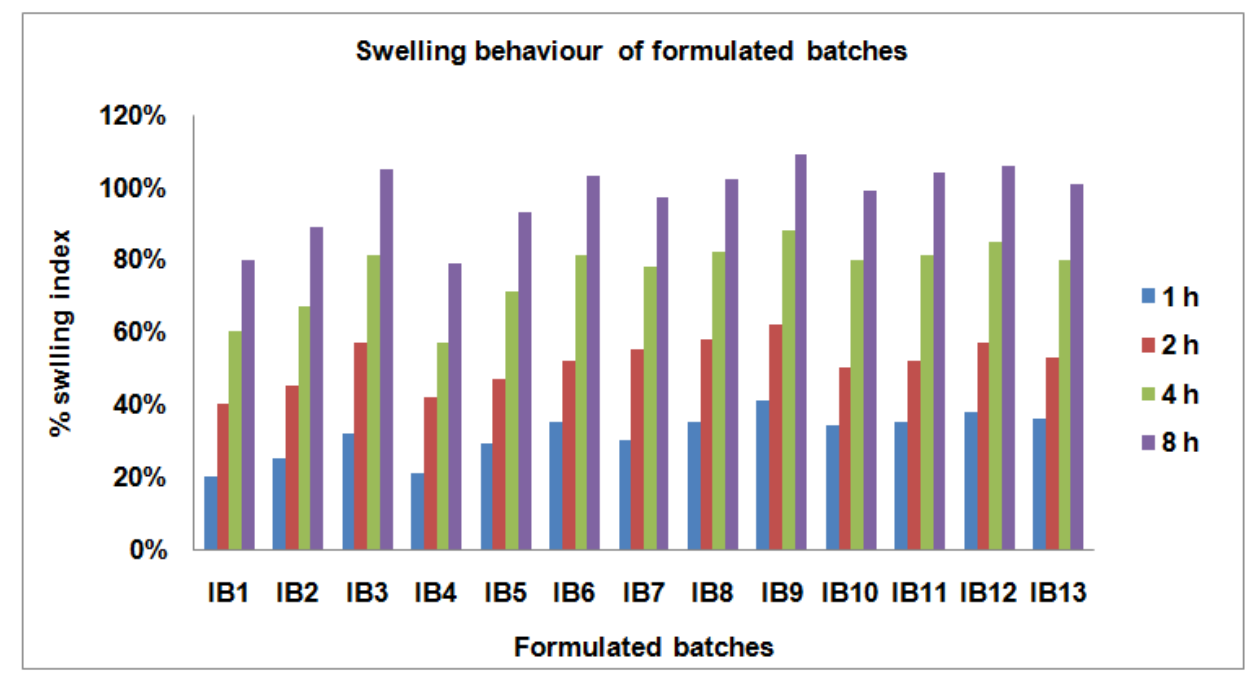

Fig. 1: Swelling behavior of formulated batches

\section{In vitro bioadhesion strength}

The values presented in table 5 indicates that all the tablets had considerable adhesion to the mucosal membrane. The bioadhesive force (mean \pm SD) reported in a range of $0.05 \pm 0.09$ to $0.18 \pm 0.06$ $\mathrm{N} / \mathrm{m}^{2}$. Formulation batch IB9 reported highest bioadhesion (mean \pm SD) of $0.18 \pm 0.06 \mathrm{~N} / \mathrm{m}^{2}$. Formulations containing more concentration of bio adhesive polymer pertains increased adhesion in comparison to other formulations.

In addition, a formulation containing carbopol 971P reported extraordinary adhesion than other two polymers. Bioadhesion a surface phenomenon in which a material of natural or synthetic origin adheres or sticks to a biological surface; usually a mucus membrane. Many water-soluble polymers stick to mucosal surfaces as they pull water from the mucus gel layer adhering to the epithelial surface and it has been defined as "adhesion by hydration".

Furthermore various kinds of adhesive force like hydrogen bonding between the adherent polymer and the substrate, which are involved in bioadhesion at the molecular level [6].

\section{Ex vivo mucoadhesion time}

The mucoadhesion residence time was found to be more with batch IB9, IB12 and IB13 (12 h), which contains carbopol 971P, and, a mixture of other three bioadhesive polymers respectively. The data has been represented in table 5 .

\section{In vitro dissolution studies}

The release of IM from FBTs varied according to the type and concentration of polymer (fig. 2). Formulation batch IB1, IB2 and IB3 containing HPMC K15M and guar gum in the ratio of $4: 1,3: 1$, and 2:1 had \% cumulative release of $94.12 \%, 89.78 \%$ and $86.45 \%$ in $10 \mathrm{~h}$ respectively. Similarly formulation batch IB4, IB5 and IB6 containing HPMC K15M and sodium alginate in the ratio of 4:1, 3:1, and 2:1 had $\%$ cumulative release of $96.15 \%, 87.67 \%$ and $80.43 \%$ in $10 \mathrm{~h}$ respectively. Further, formulation batch IB7, IB8 and IB9 containing HPMC K15M and carbopol 971P in the ratio of 4:1, 3:1, and 2:1 had $\%$ cumulative release of $98.25 \%, 92.96 \%$ and $89.32 \%$ in $10 \mathrm{~h}$ respectively. In addition, formulation batches IB10, IB11, IB12, and IB13 containing different ratios of bioadhesive polymers reported a 
\% cumulative release of $94.72 \%, 96.37 \%, 97.87 \%$ and $98.25 \%$ in 10 h respectively. Formulation batches containing carbopol 971P were reported a uniform release pattern. Furthermore, formulation batch IB9, which contained a high concentration of carbopol 971P was helped in abstaining the drug release. The drug is trapped in the glassy core when the table is in the dry state. However, when external surface hydrates, it forms a gelatinous layer like a hydrogel. The hydrogels remain intact and continuously diffuses through the gel layer at a uniform rate. In addition, carbopol 971P is a highly cross-linked polymer and has a "fuzzball" type of gel structure. It was also observed that the release rate was decreased when the viscosity and concentration of the polymer were increased. The linear relationship was found between the viscosity of the polymer and release rate of the drug from the DDS. Moreover rapid and more swelling of the tablet would lead to an increase in the dimensions of the tablet leading to an increasing in the diffusion pathways and, thus, a reduction in diffusion rate. So, the drug release was found to be high initially and then gradually decreased

Table 5: Adhesion characteristics of FBTs

\begin{tabular}{lll}
\hline Formulation batches/Characteristics & In vitro bioadhesion strength $\mathbf{~} \mathbf{N} \mathbf{m}^{2}$ ) & Ex vivo mucoadhesion time (hr) \\
\hline IB1 & $0.05 \pm 0.09$ & $7 \pm 0.7$ \\
IB2 & $0.07 \pm 0.01$ & $8 \pm 0.4$ \\
IB3 & $0.09 \pm 0.02$ & $9 \pm 0.1$ \\
IB4 & $0.06 \pm 0.03$ & $8 \pm 0.5$ \\
IB5 & $0.09 \pm 0.08$ & $9 \pm 0.7$ \\
IB6 & $0.1 \pm 0.09$ & $11 \pm 0.6$ \\
IB7 & $0.09 \pm 0.03$ & $10 \pm 0.4$ \\
IB8 & $0.12 \pm 0.01$ & $11 \pm 0.5$ \\
IB9 & $0.18 \pm 0.06$ & $12 \pm 0.1$ \\
IB10 & $0.09 \pm 0.05$ & $11 \pm 0.7$ \\
IB11 & $0.14 \pm 0.09$ & $11 \pm 0.5$ \\
IB12 & $0.16 \pm 0.02$ & $12 \pm 0.4$ \\
IB13 & $0.17 \pm 0.03$ & $12 \pm 0.5$ \\
\hline
\end{tabular}

All values are mean \pm SD; SD, Standard deviation
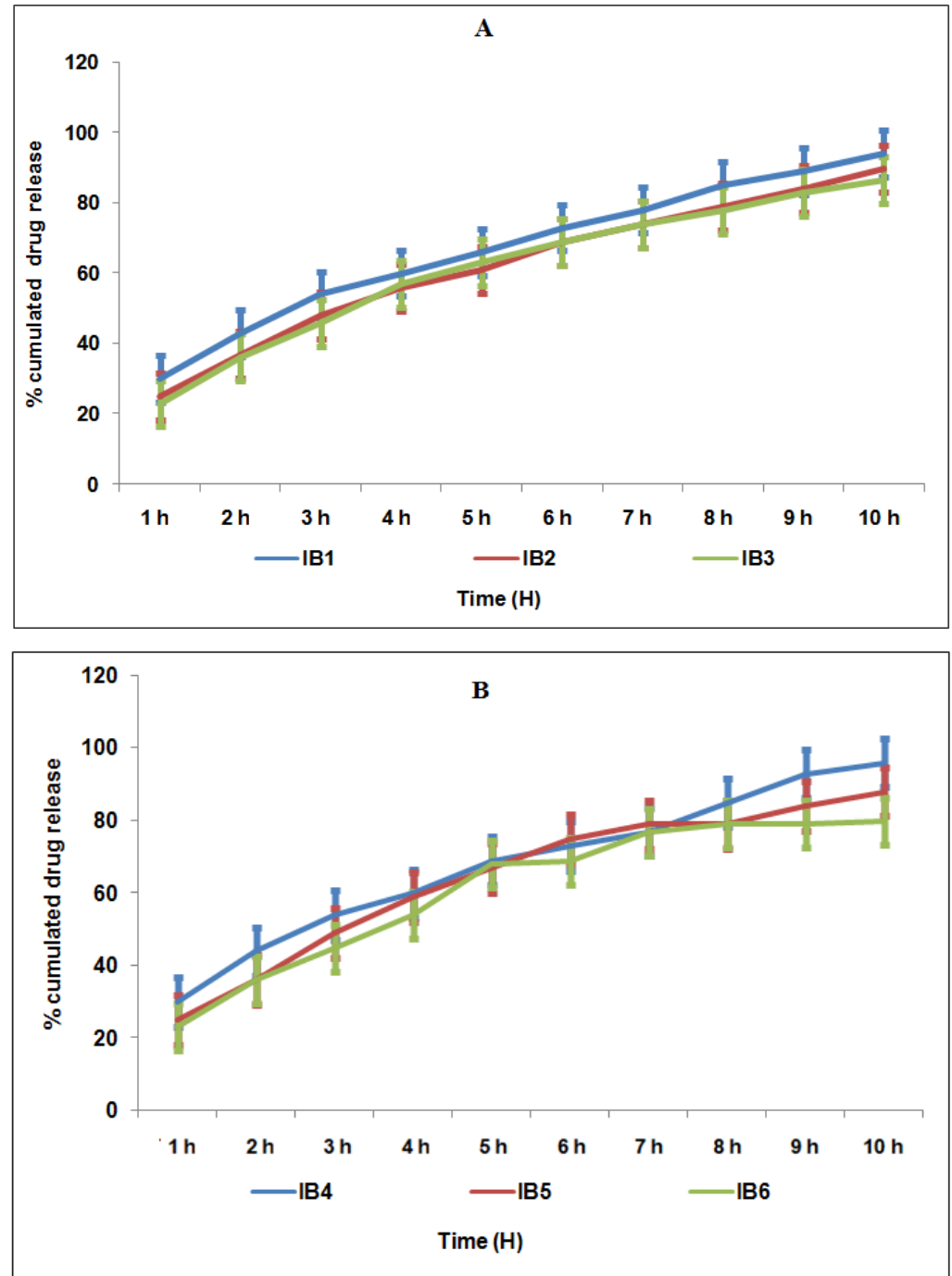

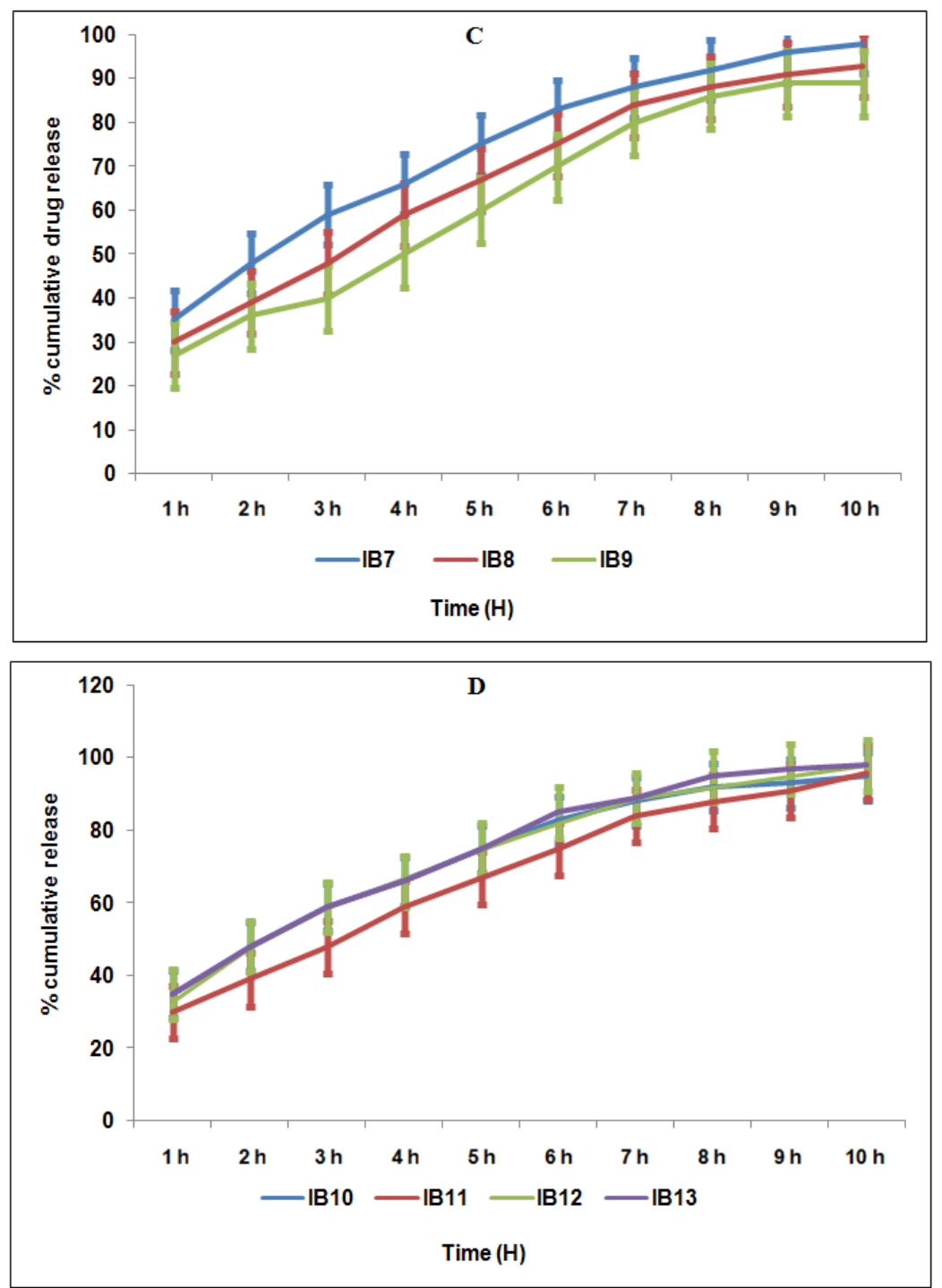

Fig. 2: Dissolution profile of FBTs, (A) formulation batches IB1-IB3, (B) formulation batches IB4-IB6, (C) formulation batches IB7-IB9,(D) formulation batches IB10-IB13

\section{Data analysis}

The data obtained from in vitro dissolution studies were fitted in a different model like zero order, first order, Higuchi and KorsmeyerPeppas model (table 6). Regression values $\mathrm{r}^{2}$ were found to be 0.61 to 0.998 for different formulations. Formulation batches IB3, IB7, IB8, and IB12 follows Korsmeyer-Peppas model. This indicates that the release mechanism is not known or more than one type of release phenomenon could be involved.

However, batch IB1, IB2, IB4, IB5, IB6, IB9, IB10, IB11, and IB13 follows Higuchi Matrix model, which indicates that the drug release is controlled by diffusion of drug through the pores. The mean diffusion exponent value (n) was found to be ranged from 0.3076 to 0.6643 .

Table 6: Kinetic data of FBTs

\begin{tabular}{|c|c|c|c|c|}
\hline Formulation batches & Zero order $\left(\mathrm{r}^{2}\right)$ & First order $\left(r^{2}\right)$ & Matrix model $\left(\mathrm{r}^{2}\right)$ & Korsemeyer-peppas model $\left(\mathrm{r}^{2}\right)$ \\
\hline IB1 & 0.8892 & 0.9972 & 0.9994 & 0.9883 \\
\hline IB2 & 0.8945 & 0.9937 & 0.9988 & 0.9867 \\
\hline IB3 & 0.8453 & 0.9768 & 0.9876 & 0.9983 \\
\hline IB4 & 0.7654 & 0.9372 & 0.9965 & 0.9854 \\
\hline IB5 & 0.8095 & 0.9675 & 0.9982 & 0.9876 \\
\hline IB6 & 0.8786 & 0.9987 & 0.9983 & 0.9878 \\
\hline IB7 & 0.8654 & 0.9678 & 0.9884 & 0.9983 \\
\hline IB8 & 0.8891 & 0.9921 & 0.9882 & 0.9896 \\
\hline IB9 & 0.7675 & 0.8072 & 0.9982 & 0.9881 \\
\hline IB10 & 0.6098 & 0.9272 & 0.998 & 0.9845 \\
\hline IB11 & 0.8876 & 0.9923 & 0.9976 & 0.9878 \\
\hline IB12 & 0.8121 & 0.8978 & 0.9876 & 0.9984 \\
\hline IB13 & 0.8098 & 0.9976 & 0.9981 & 0.9876 \\
\hline
\end{tabular}




\section{CONCLUSION}

Floating-bioadhesive DDS is an attractive alternative route for administration of drugs that have more bioavailability in upper GIT, or drugs that degraded in intestinal fluids. Tablets from all the formulation batches complied with the specified pharmacopoeia specifications in concern to physical and micromeritics characterization. Formulation batch IB9 reported a considerable swelling index, floating behavior, and more bioadhesive strength with uniform drug release pattern. Furthermore, tablets of formulation batch IB9 follow the Higuchi matrix kinetic model for the pattern of drug release. Therefore formulation batch IB9 was selected as optimized batch and were kept for further evaluation studies.

\section{ACKNOWLEDGEMENT}

The authors are very much thankful to RCPHS, Berhampur and NNRESGI, Hyderabad for providing necessary facilities for completion of the work. The authors also like to thank Celon lab Hyderabad for proving the IM.

\section{CONFLICT OF INTERESTS}

Declared none

\section{REFERENCES}

1. Nayak AK, Maji R, Das B. Gastroretentive drug delivery systems: a review. Asian J Pharm Clin Res 2010;3:1-9.

2. Chen YC, Ho HO, Liu DZ, Siow WS, Sheu MT. Swelling/floating capability and drug release characterizations of gastro-retentive drug delivery system based on a combination of hydroxyethyl cellulose and sodium carboxymethylcellulose. PloS One 2015;10:e0116914. Doi:10.1371/ journal. pone. 0116914.
3. Panigrahy RN, Gudipati S, Chinnala KM. Design, development and in vitro evaluation of combined floating-bioadhesive drug delivery systems of atenolol. Int J Pharm Pharm Sci 2016;8:41-6.

4. Panigrahy RN, Mahale AM, Dhaked PS. Formulation and in vitro evaluation of combined floating-mucoadesive tablet of metoprolol succinate. Int J Pharm Pharm Sci 2011;3:221-6.

5. Mandal UK, Chatterjee B, Senjoti FG. Gastro-retentive drug delivery systems and their in vivo success: a recent update. Asian J Pharm Sci 2016;11:575-84.

6. Panigrahy RN, Mahale AM, Sakarkar DM. Design development and in vitro testing of a combined bioadhesive-floating oral drug delivery system. J Pharm Res 2011;4:2212-5.

7. Drug Bank: Imatinib (DB00619) [Internet]. Available from: http://www.drugbank.ca/.

http://www.drugbank.ca/drugs/DB00619]. [Last accessed on 10 Mar 2017].

8. De Kogel CE, Schellens JH. Imatinib. Oncologist 2007;12:1390-4.

9. Kadivar A, Kamalidehghan B, Javar HA, Davoudi ET, Zaharuddin $\mathrm{ND}$, Sabeti B, et al. Formulation and in vitro, in vivo evaluation of effervescent floating sustained-release imatinib mesylate tablet. PloS One 2015;10:e0126874. Doi:10.1371/ journal. pone. 0126874

10. The government of India, ministry of health and family welfare. The Pharmacopoeia of India. Controller of publication; 2014.

11. (USP) TUSP. h711iDISSOLUTION. Apparatus 2 (Paddle Apparatus). Rockville, USA: The United States Pharmacopeial Convention (USP); 2011.

12. Biswal B, Parmar H, Nayak J. Design development and evaluation of buccal tablet containing nicorandil as a model drug. Int J Pharm Pharm Sci 2015;8:102-6. 